Research article

Open Access

\title{
Maintenance treatment with esomeprazole following initial relief of non-steroidal anti-inflammatory drug-associated upper gastrointestinal symptoms: the NASA2 and SPACE2 studies
}

\author{
Christopher J Hawkey ${ }^{1}$, Nicholas J Talley², James M Scheiman³, Roger H Jones ${ }^{4}$, \\ Göran Långström ${ }^{5}$, Jorgen Næsdal ${ }^{5}$, Neville D Yeomans 6 for the NASA/SPACE author group
}

\author{
${ }^{1}$ Institute of Clinical Research, Trials Unit, Wolfson Digestive Diseases Centre, University Hospital, Derby Road, Nottingham, NG7 2 UH, UK \\ 2Mayo Clinic College of Medicine, 200 First Street SW, Rochester, MN 55905, USA \\ ${ }^{3}$ Division of Gastroenterology, Department of Internal Medicine, University of Michigan Medical Center, 3912 Taubman Center, Ann Arbor, MI 48109- \\ 0362 , USA \\ ${ }^{4}$ GKT Department of General Practice, King's College, 5 Lambeth Walk, London, SE11 6SP, UK \\ ${ }^{5}$ AstraZeneca R\&D, Karragatan 5, Pepparedsleden 1, Mölndal 431 83, Sweden \\ ${ }^{6}$ Medical School, University of Western Sydney, Locked Bag 1797, Penrith South DC, NSW 1797, Australia \\ Corresponding author: Christopher J Hawkey, cj.hawkey@nottingham.ac.uk
}

Received: 21 Dec 2005 Revisions requested: 26 Jan 2006 Revisions received: 3 Nov 2006 Accepted: 9 Feb 2007 Published: 9 Feb 2007

Arthritis Research \& Therapy 2007, 9:R17 (doi:10.1186/ar2124)

This article is online at: http://arthritis-research.com/content/9/1/R17

(c) 2007 Hawkey et al.; licensee BioMed Central Ltd.

This is an open access article distributed under the terms of the Creative Commons Attribution License (http://creativecommons.org/licenses/by/2.0), which permits unrestricted use, distribution, and reproduction in any medium, provided the original work is properly cited.

\begin{abstract}
Non-steroidal anti-inflammatory drugs (NSAIDs), including selective cyclo-oxygenase-2 (COX-2) inhibitors, cause upper gastrointestinal (Gl) symptoms that are relieved by treatment with esomeprazole. We assessed esomeprazole for maintaining long-term relief of such symptoms. Six hundred and ten patients with a chronic condition requiring anti-inflammatory therapy who achieved relief of NSAID-associated symptoms of pain, discomfort, or burning in the upper abdomen during two previous studies were enrolled and randomly assigned into two identical, multicentre, parallel-group, placebo-controlled studies of esomeprazole $20 \mathrm{mg}$ or $40 \mathrm{mg}$ treatment (NASA2 [Nexium Anti-inflammatory Symptom Amelioration] and SPACE2 [Symptom Prevention by Acid Control with Esomeprazole] studies; ClinicalTrials.gov identifiers NCT00241514 and NCT00241553, respectively) performed at various rheumatology, gastroenterology, and primary care clinics. Four hundred and twenty-six patients completed the 6-month treatment period. The primary measure was the proportion of
\end{abstract}

patients with relapse of upper Gl symptoms, recorded in daily diary cards, after 6 months. Relapse was defined as moderateto-severe upper Gl symptoms (a score of more than or equal to 3 on a 7-grade scale) for 3 days or more in any 7-day period. Esomeprazole was significantly more effective than placebo in maintaining relief of upper GI symptoms throughout 6 months of treatment. Life-table estimates (95\% confidence intervals) of the proportion of patients with relapse at 6 months (pooled population) were placebo, $39.1 \%(32.2 \%$ to $46.0 \%)$; esomeprazole $20 \mathrm{mg}, 29.3 \%(22.3 \%$ to $36.2 \%)$ ( $p=0.006$ versus placebo); and esomeprazole $40 \mathrm{mg}, 26.1 \%$ (19.4\% to $32.9 \%$ ) ( $p=0.001$ versus placebo). Patients on either nonselective NSAIDs or selective COX-2 inhibitors appeared to benefit. The frequency of adverse events was similar in the three groups. Esomeprazole maintains relief of NSAID-associated upper Gl symptoms in patients taking continuous NSAIDs, including selective COX-2 inhibitors.

\section{Introduction}

Continuous users of non-steroidal anti-inflammatory drugs (NSAIDs) often experience treatment-associated upper gastrointestinal (Gl) side effects, including upper abdominal pain and heartburn [1-3]. Although recently introduced drugs that selectively inhibit the cyclo-oxygenase-2 (COX-2) enzyme (selective COX-2 inhibitors) were expected to have better GI tolerability, it is clear that these drugs are also associated with

$\mathrm{AE}=$ adverse event; COX-2 = cyclo-oxygenase-2; GERD = gastroesophageal reflux disease; GI = gastrointestinal; GSRS = Gastrointestinal Symptom Rating Scale; HRQL = health-related quality of life; NASA = Nexium Anti-inflammatory Symptom Amelioration; NSAID = non-steroidal anti-inflammatory drug; PPI = proton pump inhibitor; QOLRAD = Quality of Life in Reflux and Dyspepsia; SPACE = Symptom Prevention by Acid Control with Esomeprazole. 
a substantial level of drug-related symptomatic upper GI adverse events (AEs) requiring treatment $[4,5]$.

Upper Gl symptoms, together with the underlying inflammatory disease, lead to substantial reductions in health-related quality of life (HRQL) in patients taking long-term NSAID therapy $[6,7]$ and often lead to dose reduction or discontinuation of NSAID treatment $[3,8]$. Treatments that relieve upper GI symptoms associated with NSAIDs may thus allow patients to continue therapy with these drugs. However, it is important that such additional treatments are themselves well tolerated and effective for long periods of time given that many patients with chronic inflammatory conditions require continuous NSAID therapy for many years.

In animal studies, NSAID-associated gastric mucosal damage has been shown to be highly $\mathrm{pH}$-dependent [9]. Consequently, a combination of NSAID treatment and acid suppressive therapy may minimise the risk of NSAID toxicity and associated upper Gl symptoms, and human studies have established a major role for proton pump inhibitors (PPIs) in this regard $[10,11]$. In addition, there are growing indications that PPIs are effective in relieving the upper Gl symptoms associated with the use of NSAIDs, including selective COX2 inhibitors [12].

We therefore conducted two pairs of placebo-controlled studies that evaluated the efficacy, tolerability, and safety of acid suppression with esomeprazole in the treatment and prevention of NSAID-associated upper Gl symptoms. Each study consisted of an acute and a maintenance study. The acute 4week symptom relief studies (Nexium Anti-inflammatory Symptom Amelioration [NASA1] and Symptom Prevention by Acid Control with Esomeprazole [SPACE1] studies) have shown that esomeprazole (20 and $40 \mathrm{mg}$ ) relieves upper Gl symptoms in patients using NSAIDs, including selective COX-2 inhibitors [12]. In this paper, we report a comparison of esomeprazole 20 and $40 \mathrm{mg}$ with placebo in the long-term (6 months) maintenance of relief of upper abdominal pain, discomfort, or burning in patients continuing to use NSAIDs, including selective COX-2 inhibitors.

\section{Materials and methods Study design}

Two 6-month randomised, double-blind, parallel-group, placebo-controlled studies (NASA2 [SH-NEN-0002] and SPACE2 [SH-NEN-0004]) were conducted in 149 outpatient centres, including rheumatology, gastroenterology, and primary care, in Europe, USA, Canada, South Africa, and Australia. Signed informed consent was obtained from all patients prior to entry into the study. The study was approved by an independent ethics committee.

\section{Patients}

Patients (male and female, at least 18 years old) who achieved relief of upper Gl symptoms (pain, discomfort, or burning in the upper abdomen) in the NASA1 and SPACE1 studies, whether taking placebo, esomeprazole $20 \mathrm{mg}$, or esomeprazole $40 \mathrm{mg}$, were eligible for immediate inclusion in the subsequent 6month maintenance studies. Relief during the acute studies was defined as having a diary assessment of 'none' or 'minimal' (scores of 0 or 1 , respectively, on a 7-grade scale) on at least 5 of the final 7 days and no more than 'mild' (a score of 2) on no more than 2 days. Patients satisfying these criteria were rerandomised (in equal proportion in blocks of six according to a computer-generated randomisation list) upon entry to the 6month studies to receive esomeprazole $20 \mathrm{mg}$, esomeprazole $40 \mathrm{mg}$, or placebo once daily for 6 months, in addition to their NSAID therapy.

All patients included had a chronic condition requiring continuous daily treatment with one or more oral NSAIDs (including selective COX-2 inhibitors and high-dose aspirin [>325 mg/ day]) for at least 5 days in any given week for the duration of the study. Patients using low-dose aspirin ( $<325 \mathrm{mg} /$ day) in conjunction with an NSAID or COX-2 inhibitor were allowed to participate in the study but were categorised as receiving nonselective NSAID therapy (reflecting the COX-1 inhibitory effects of this therapy) regardless of whether aspirin was used alone or in combination with a non-selective NSAID or a selective COX-2 inhibitor. For assessment of the effect of NSAID type on study variables, patients were included in the selective COX-2 inhibitor group only if they were taking a selective COX-2 inhibitor alone.

Exclusion criteria included pain, discomfort, or burning in the upper abdomen precipitated by exercise, relieved by defecation, or not associated with the use of NSAIDs; a history of symptomatic gastroesophageal reflux disease (GERD) not associated with the use of NSAIDs; a history of erosive esophagitis, gastric, or duodenal ulcer or of esophageal, gastric, or duodenal surgery; a need for concomitant therapy with drugs likely to affect the outcome of the study (stable treatment with disease-modifying anti-rheumatic drugs was permitted, as was limited glucocorticoid use).

\section{Assessments}

The severity of NSAID-associated upper GI symptoms (pain, discomfort, or burning in the upper abdomen) was rated by the patient on daily diary cards on a 7-grade scale from 0 (none: no symptoms) to 6 (very severe: cannot be ignored and markedly limits daily activities and often requires rest). In addition, at baseline and after 1, 3, and 6 months, the severity of four other upper $\mathrm{Gl}$ symptoms during the previous 7 days (heartburn, acid regurgitation, upper abdominal bloating, and nausea) was assessed by the investigator and graded from 0 (none: no symptoms) to 3 (severe: incapacitating with inability to perform normal activities). 
Upper Gl symptom severity and HRQL were also assessed using two validated patient-reported outcome instruments, the Gastrointestinal Symptom Rating Scale (GSRS) [13] and the Quality of Life in Reflux and Dyspepsia (QOLRAD) questionnaire $[14,15]$. Both instruments use 7-grade Likert scales and group related aspects into five dimensions: reflux, abdominal pain, indigestion, diarrhoea, and constipation (for the GSRS) and emotional distress, sleep disturbance, food/drink problems, vitality, and physical/social functioning (for the QOLRAD questionnaire). The QOLRAD questionnaire is a disease-specific instrument that was developed for patients with upper GI symptoms, including heartburn and dyspepsia. The GSRS is also a disease-specific instrument and was developed specifically to assess Gl symptom severity. Mean change from baseline in the three OOLRAD dimensions of emotional distress, sleep disturbance, and food/drink problems was assessed, as was mean change from baseline in the three GSRS dimensions of reflux, abdominal pain, and indigestion. Compliance with NSAIDs and with the study drug was monitored by diary cards and by the investigator (counting unused tablets), respectively. AEs were monitored at 1,3 , and 6 months by the investigator.

\section{Statistical analyses}

The primary variable was the proportion of patients with relapse of upper GI symptoms associated with the use of daily NSAIDs, including selective COX-2 inhibitors, after 6 months of treatment. Relapse was defined as moderate-to-severe upper Gl symptoms (more than or equal to 3 on the 7-grade severity scale) on at least 3 days in any 7-day period. The proportions of patients with relapse of upper Gl symptoms were analysed by life-table analysis (Kaplan-Meier estimates of time to first event) with differences between active treatment and placebo compared using the log-rank test. This analysis was performed for all patients and for those in the non-selective NSAID or selective COX-2 inhibitor subgroups. For analysis of the primary variable, the study populations were analysed separately. The two study populations were pooled for the assessment of the effect of NSAID type (non-selective versus selective COX-2 inhibitor).

The number needed to treat was calculated as the number of patients who need to be treated with esomeprazole 20 or 40 $\mathrm{mg}$ to avoid one case of upper $\mathrm{Gl}$ symptom relapse, relative to placebo, during 6 months of treatment. Secondary variables included mean change in the three dimensions pre-specified as relevant to upper GI symptoms on each of the GSRS and QOLRAD questionnaires from baseline to last visit, analysed by analysis of covariance. The proportion of patients maintained free of investigator-assessed symptoms of heartburn, acid regurgitation, upper abdominal bloating, and nausea at 6 months was assessed post hoc with differences analysed by the Fisher exact test. A post hoc regression analysis using a Cox proportional hazards model was also performed to assess the influence of the following factors on time to relapse of pain, discomfort, or burning in the upper abdomen: age (less than 65 versus more than or equal to 65 years), gender (male versus female), Helicobacter pylori status (positive versus negative), selective COX-2 inhibitors (yes versus no), treatment during NASA1/SPACE1 (esomeprazole $40 \mathrm{mg}$, esomeprazole $20 \mathrm{mg}$, placebo), and treatment during NASA2/SPACE2 (esomeprazole $40 \mathrm{mg}$, esomeprazole $20 \mathrm{mg}$, placebo).

To determine the reliability of diary card measurements, the correlation coefficient for 7 days of diary card recordings was estimated using the GSRS abdominal pain domain. Pearson correlations between GSRS abdominal pain and mean of diary cards for the last 7 days were also assessed in terms of baseline values, last values, and change from baseline.

Each study was planned to include 300 patients in order to provide $90 \%$ power to detect a difference in upper Gl symptom relapse rates of $19 \%$ for the esomeprazole groups and $42 \%$ for the placebo group at the significance level of 0.025 using the Fisher exact test. This was based on observed differences in relapse rates of respective variables between study drug and placebo in the ASTRONAUT (Acid Suppression Trial: Ranitidine versus Omeprazole for NSAID-Associated Ulcer Treatment) [11] and OMNIUM (Omeprazole versus Misoprostol for NSAID-Induced Ulcer Management) [10] studies.

\section{Results}

Of 334 and 276 patients randomly assigned, 328 and 276 patients constituted the intention-to-treat populations for NASA2 and SPACE2, respectively. Enrolment for the NASA2 and SPACE2 studies started in February and April 2001, respectively, and the last patient completed both studies in February 2003. The flow of patients through the studies is shown in Figure 1. At study entry, the treatment groups were similar with respect to demographic and clinical characteristics, although slightly more patients receiving placebo during the maintenance phase had received esomeprazole $20 \mathrm{mg}$ than either esomeprazole $40 \mathrm{mg}$ or placebo during the acute phase (Table 1). The most common NSAIDs during maintenance treatment were rofecoxib $(21 \%)$, celecoxib $(20 \%)$, diclofenac (20\%), ibuprofen (9\%), piroxicam (4\%), and naproxen (3\%). The proportion of patients compliant with study drug (mean dosing: $75 \%$ to $125 \%$ relative to protocol) was more than $90 \%$ in all three treatment arms. Patient compliance with NSAID treatment (drugs used on at least $70 \%$ of days according to diary data) was similarly high (more than $90 \%$ of patients) in the three treatment arms in both studies. The diary card measurements demonstrated good reliability; the estimated correlation coefficient for the mean of 7 days of measurements (using GSRS abdominal pain score) was 0.62. Furthermore, the correlation between GSRS abdominal pain and the mean diary card measurements for the preceding 7 days ranged from 0.52 to 0.74 for the baseline values, last values, and change from baseline, indicating satisfactory validity. 


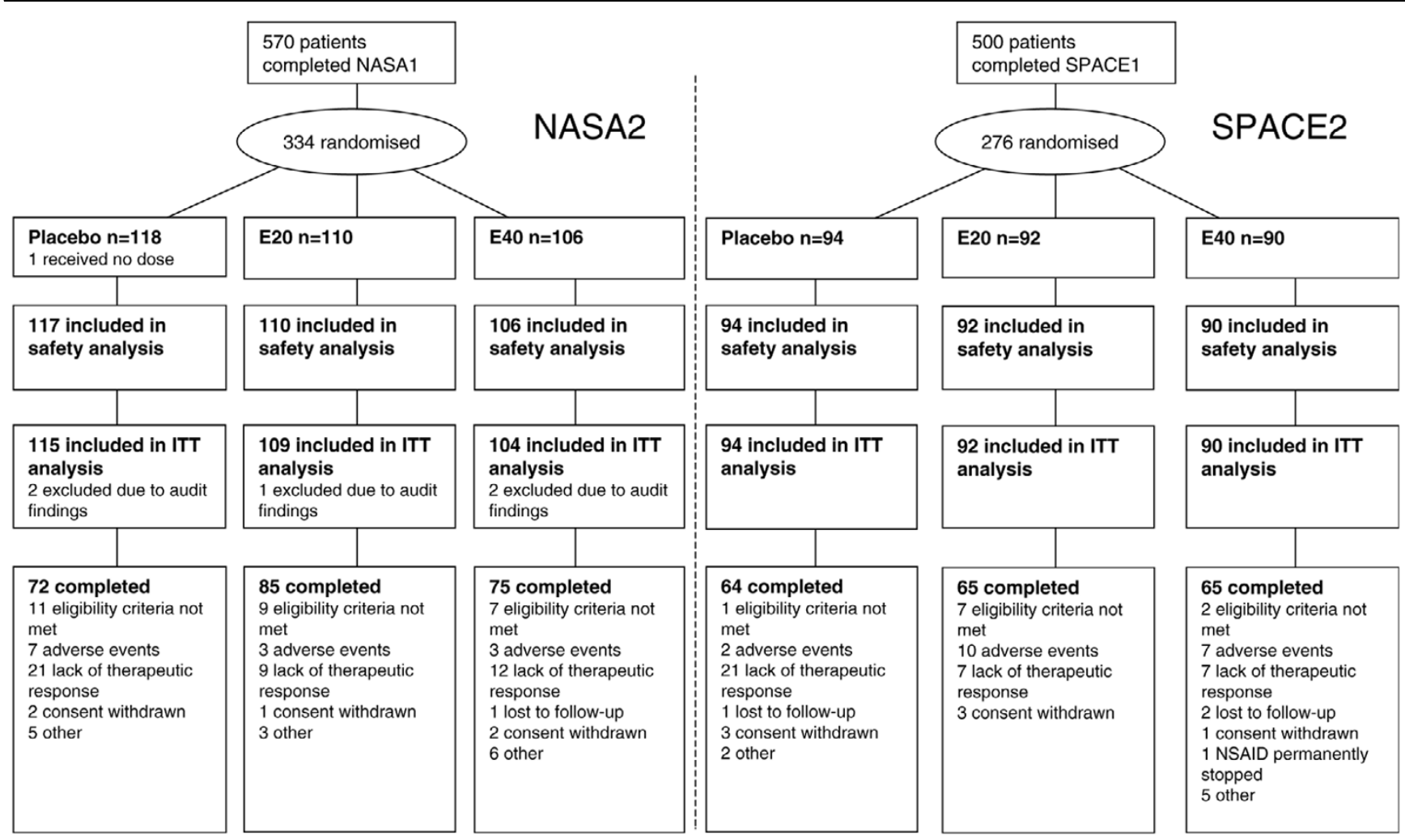

Flow diagram of patients through the studies. E20, esomeprazole $20 \mathrm{mg}$; E40, esomeprazole $40 \mathrm{mg}$; ITT, intention-to-treat; NSAID, non-steroidal anti-inflammatory drug.

\section{Efficacy}

Significantly fewer patients on esomeprazole 20 or $40 \mathrm{mg}$, compared with placebo, experienced relapse of upper $\mathrm{Gl}$ symptoms (upper abdominal pain, discomfort, or burning) based on diary data (Figure 2a). Among patients who were treated with esomeprazole (either 20 or $40 \mathrm{mg}$ ) during the acute phase and who went on to receive placebo during the maintenance phase, high rates of relapse were observed (Figure $2 b$ ). Patients with an apparent response to placebo treatment during the acute phase had a lower relapse rate when treated with placebo during the maintenance phase than those who received active treatment during the maintenance phase. Relapse rates were, in general, lower in those who received esomeprazole during the maintenance phase, regardless of initial therapy. Data for the individual trials are shown in Table 2. Number needed to treat analysis showed that, throughout 6 months of treatment, 11 and 8 patients need to be treated with esomeprazole $20 \mathrm{mg}$ or esomeprazole $40 \mathrm{mg}$, respectively, in order to avoid 1 patient experiencing relapse of upper $\mathrm{Gl}$ symptoms. The exploratory regression analysis identified three factors as having a significant effect on time to relapse of upper Gl symptoms. Treatment with esomeprazole $20 \mathrm{mg}$ or esomeprazole $40 \mathrm{mg}$ was associated with a significant reduction in upper Gl symptoms $(p=0.0035$ and $p=0.0017$, respectively). Patients younger than 65 years old were significantly more likely than those 65 years old or older to experience a relapse of upper $\mathrm{Gl}$ symptoms $(p=0.0284)$. No other variables included in the analysis were identified as having a significant effect on time to relapse of symptoms.

\section{Analysis by NSAID type}

When patients taking non-selective NSAIDs or selective COX2 inhibitors were analysed separately, fewer patients on esomeprazole experienced relapse of upper Gl symptoms compared with those on placebo (Figure 2c,d). Post hoc analyses showed statistically significant differences for both doses of esomeprazole versus placebo among those using nonselective NSAIDs and for esomeprazole $40 \mathrm{mg}$ among those using selective COX-2 inhibitors.

\section{Other individual investigator-assessed symptoms}

As for upper abdominal pain, discomfort, or burning, the proportion of patients with investigator-assessed heartburn, acid regurgitation, nausea, and upper abdominal bloating at the 6month visit was significantly lower in patients treated with esomeprazole (both 20 and $40 \mathrm{mg}$ ) than with placebo (Figure 3). 
Table 1

\begin{tabular}{|c|c|c|c|}
\hline \multirow[b]{2}{*}{ Characteristic } & \multicolumn{3}{|c|}{ Pooled population } \\
\hline & Placebo $(n=209)$ & Esomeprazole $20 \mathrm{mg}(n=201)$ & Esomeprazole $40 \mathrm{mg}(n=194)$ \\
\hline Male/female gender, percentage & 27.3:72.7 & 21.4:78.6 & 24.2: 75.8 \\
\hline Age in years, mean (standard deviation) & $57.1(13.4)$ & $54.4(11.9)$ & $55.7(13.6)$ \\
\hline \multicolumn{4}{|l|}{ Type of chronic condition, percentage } \\
\hline Rheumatoid arthritis & 24.4 & 18.4 & 20.6 \\
\hline Osteoarthritis & 43.1 & 45.3 & 42.8 \\
\hline Other chronic condition & 32.5 & 36.3 & 36.6 \\
\hline $\begin{array}{l}\text { Time since first diagnosis of chronic } \\
\text { condition in years, median }\end{array}$ & 9 & 7 & 9 \\
\hline \multicolumn{4}{|l|}{$\begin{array}{l}\text { Helicobacter pylori status (histology), } \\
\text { percentage }^{\mathrm{a}}\end{array}$} \\
\hline Negative & 95.7 & 93.0 & 95.9 \\
\hline Positive & 3.3 & 6.5 & 3.1 \\
\hline Unknown & 1.0 & 0.5 & 1.0 \\
\hline \multicolumn{4}{|l|}{ NSAID type, percentage } \\
\hline Non-selective & 64.1 & 65.7 & 67.0 \\
\hline Selective COX-2 inhibitor & 35.9 & 34.3 & 33.0 \\
\hline \multicolumn{4}{|l|}{ Study drug in acute study, percentage } \\
\hline Placebo & 24.4 & 29.3 & 32.5 \\
\hline Esomeprazole $20 \mathrm{mg}$ & 43.1 & 32.8 & 36.1 \\
\hline Esomeprazole $40 \mathrm{mg}$ & 32.5 & 37.8 & 31.4 \\
\hline
\end{tabular}

a $H$. pylori status derived from the acute studies (NASA1 [Nexium Anti-inflammatory Symptom Amelioration] and SPACE1 [Symptom Prevention by Acid Control with Esomeprazole]). COX-2, cyclo-oxygenase-2; NSAID, non-steroidal anti-inflammatory drug.

Table 2

\section{Estimated proportion of patients with relapse of upper gastrointestinal symptoms}

\begin{tabular}{lcccc}
\hline & NASA2 study & $p$ value versus placebo & SPACE2 study & $p$ value versus placebo \\
\hline Placebo & $38.2 \%$ & - & $39.8 \%$ & - \\
Esomeprazole $20 \mathrm{mg}$ & $28.3 \%$ & 0.04 & $30.7 \%$ & 0.07 \\
Esomeprazole $40 \mathrm{mg}$ & $24.3 \%$ & 0.004 & $28.4 \%$ & 0.05 \\
\hline
\end{tabular}

Kaplan-Meier life-table estimates of proportion of patients with relapse of pain, discomfort, or burning in the upper abdomen throughout 6 months of treatment with esomeprazole $20 \mathrm{mg}$, esomeprazole $40 \mathrm{mg}$, or placebo and log-rank comparisons for the individual studies. NASA, Nexium Antiinflammatory Symptom Amelioration; SPACE, Symptom Prevention by Acid Control with Esomeprazole.

\section{Patient-reported outcomes}

Baseline GSRS mean scores for the three relevant dimensions were between 1.49 and 2.00 ( $1=$ no symptoms, $7=$ most severe symptoms). At 6 months, esomeprazole $20 \mathrm{mg}$ and $40 \mathrm{mg}$ were significantly more effective than placebo at maintaining previous symptom improvements for the GSRS dimensions of reflux (esomeprazole $20 \mathrm{mg}$ : $p=0.002$, esomeprazole $40 \mathrm{mg}: p=0.0002)$ and abdominal pain (esomeprazole $20 \mathrm{mg}$ : $p=0.006$, esomeprazole $40 \mathrm{mg}$ : $p=$
0.002). A significant difference was also observed between esomeprazole $20 \mathrm{mg}$ and placebo for the indigestion dimension (esomeprazole $20 \mathrm{mg}$ : $p=0.03$, esomeprazole $40 \mathrm{mg}$ : $p$ $=0.11$ ) (Figure 4a).

Baseline QOLRAD mean scores for the three pre-specified relevant dimensions were between 6.30 and $6.59(7=$ no impairment of HRQL, 1 = most severe impairment) following improvements in the acute treatment studies [12]. At 6 
Figure 2

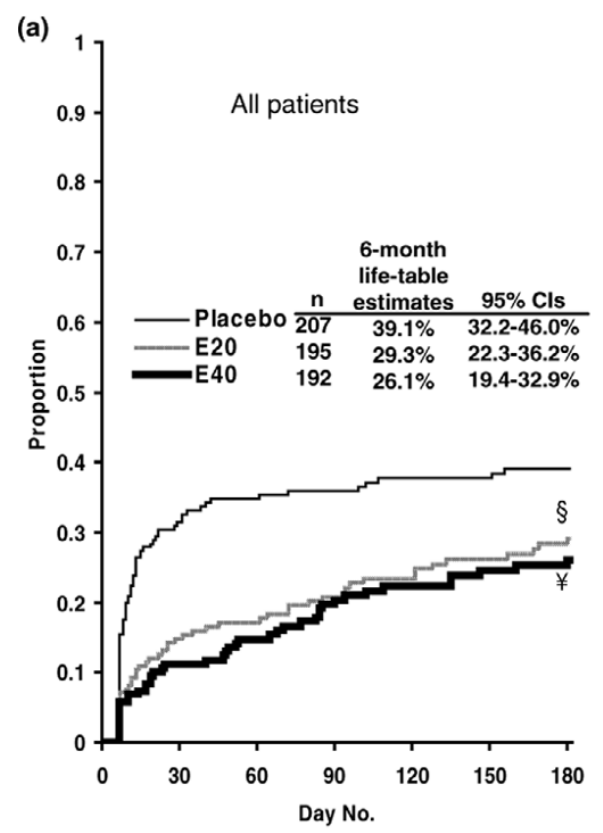

(c)

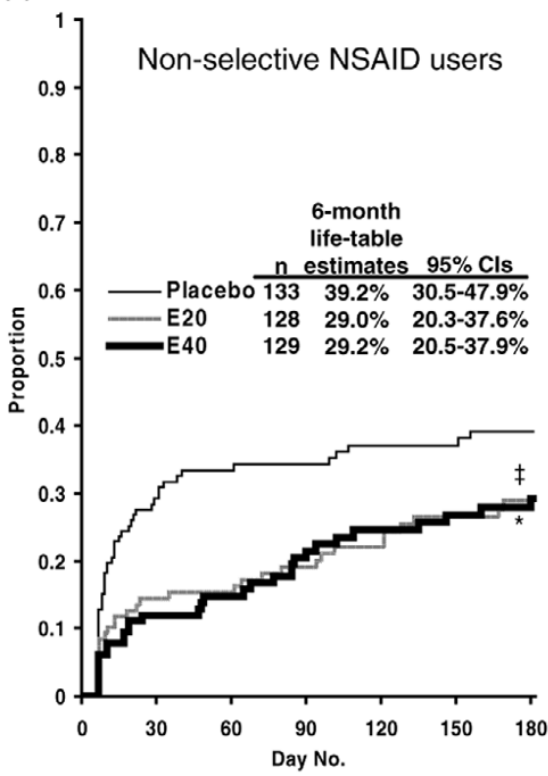

(d)

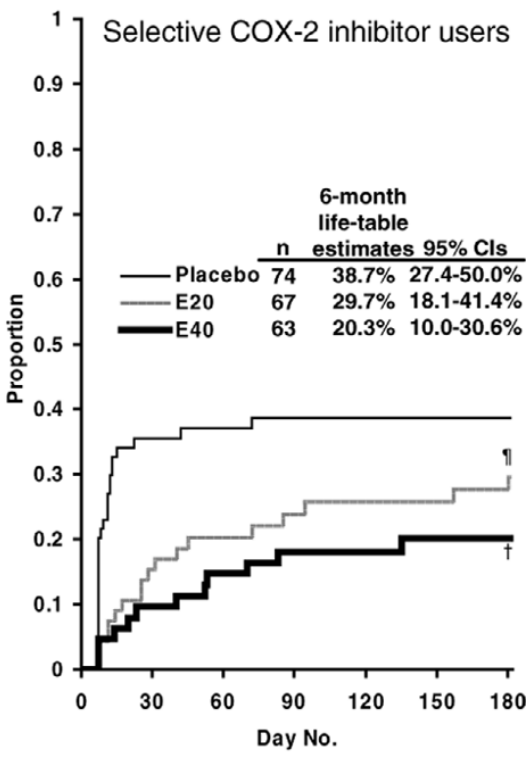

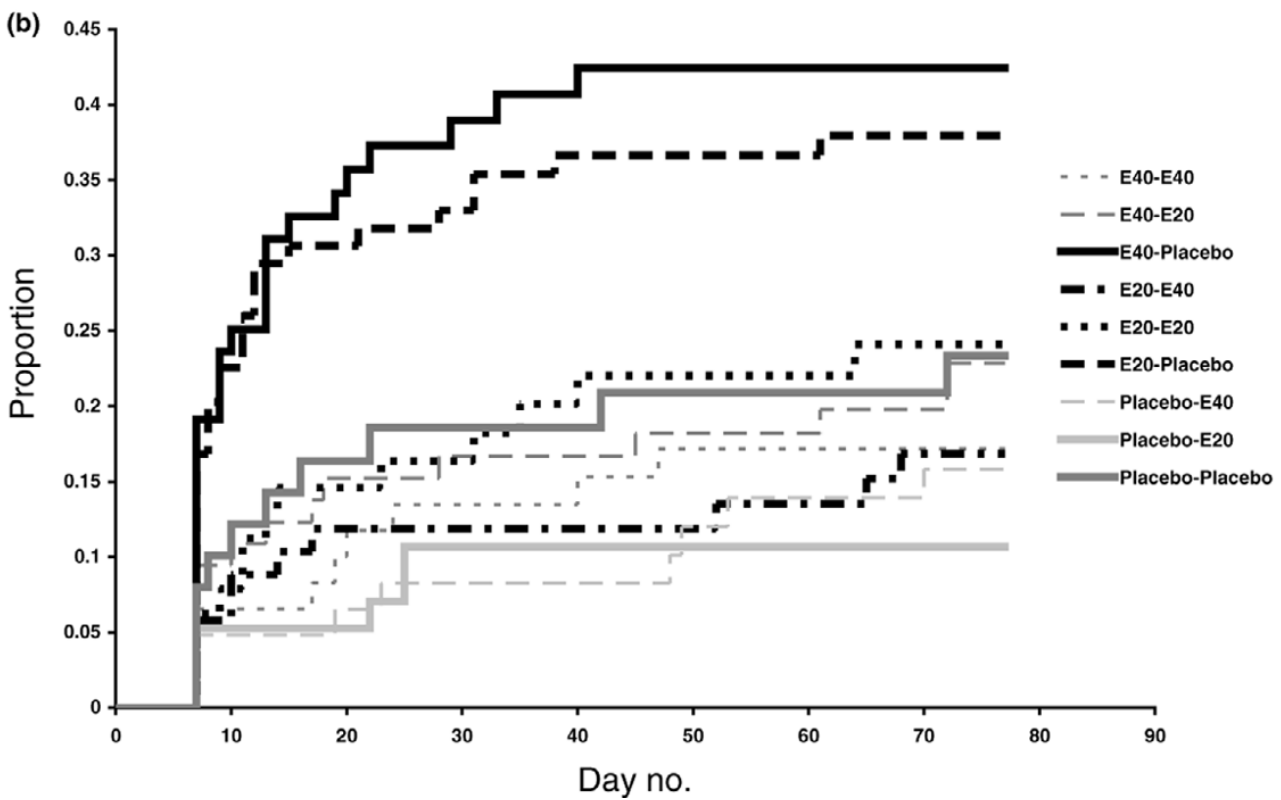

Estimated proportion of patients with relapse of upper gastrointestinal symptoms. Kaplan-Meier life-table analyses of the proportion of patients with relapse of pain, discomfort, or burning in the upper abdomen throughout 6 months of treatment with esomeprazole 20 mg (E20), esomeprazole 40 $\mathrm{mg}$ (E40), or placebo (a) for all patients, (b) according to treatment in the acute and maintenance studies, (c) for non-selective non-steroidal antiinflammatory drug (NSAID) users, and (d) for selective cyclo-oxygenase-2 (COX-2) NSAID users (pooled intention-to-treat population). Diary card data were not available for 10 patients (placebo, $n=2$; esomeprazole $20 \mathrm{mg}, n=6$; esomeprazole $40 \mathrm{mg}, n=2$ ). ${ }^{\S} p=0.006,{ }^{\ddagger} p=0.001,{ }^{\ddagger} p=$ $0.03,{ }^{*} p=0.02, \uparrow p=0.08,{ }^{\dagger} p=0.01$, all versus placebo. $\mathrm{Cl}$, confidence interval.

months, esomeprazole 20 and 40 mg were significantly more effective than placebo for maintaining improvements in HRQL as judged by mean changes in the QOLRAD questionnaire dimensions of sleep disturbance (esomeprazole $20 \mathrm{mg}: p=$ 0.02 , esomeprazole $40 \mathrm{mg}: p=0.005$ ) and food/drink problems (esomeprazole $20 \mathrm{mg}$ : $p=0.003$, esomeprazole $40 \mathrm{mg}$ : $p=0.004)$. Esomeprazole $40 \mathrm{mg}$ was also significantly more effective than placebo for the emotional distress dimension (esomeprazole $20 \mathrm{mg}$ : $p=0.05$, esomeprazole $40 \mathrm{mg}$ : $p=$ 0.004) (Figure 4b).

\section{Safety and tolerability}

Esomeprazole 20 and $40 \mathrm{mg}$ were well tolerated in combination with continuous daily NSAID use, and no safety concerns 


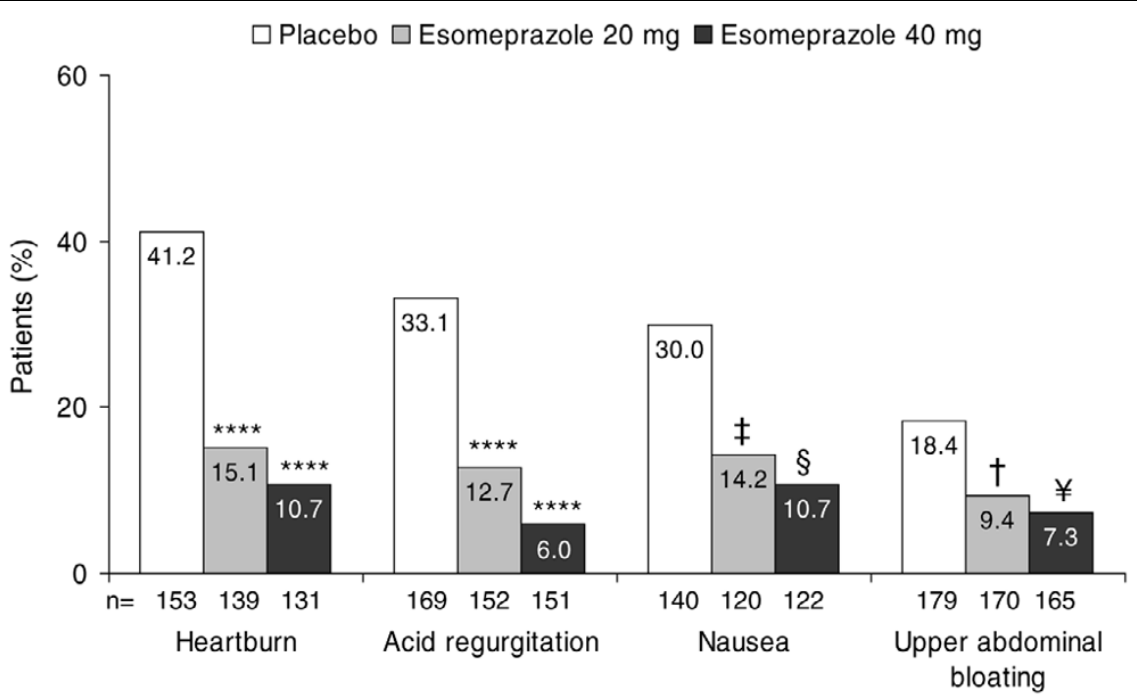

Proportion of patients with investigator-assessed symptoms in the week preceding the 6-month visit (pooled intention-to-treat population). Numbers (n) relate to patients without the individual symptom upon entering the 6 -month maintenance phase. ${ }^{\dagger} p=0.02,{ }^{\ddagger} p=0.002,{ }^{\ddagger} p=0.003,{ }^{\S} p=0.0001$, ${ }^{* * \star *} p<0.0001$, all versus placebo.

were raised. In the pooled population, $\mathrm{AEs}$ and discontinuations due to AEs occurred in $47.4 \%$ and $8.5 \%$ of placebo recipients, $55.9 \%$ and $7.4 \%$ of patients treated with esomeprazole $20 \mathrm{mg}$, and $54.6 \%$ and $6.1 \%$ of patients taking esomeprazole $40 \mathrm{mg}$, respectively. Serious AEs occurred in $5.2 \%$ of placebo recipients, $5.0 \%$ of patients taking esomeprazole $20 \mathrm{mg}$, and $7.1 \%$ of patients taking esomeprazole 40 mg. Neither of the two deaths (both due to pancreatic carcinoma, one in the placebo arm and one in the esomeprazole 40 $\mathrm{mg}$ arm) in the study was assessed as related to the study drug.

\section{Discussion}

In the two 4-week studies that directly preceded the two studies reported here, esomeprazole 20 and $40 \mathrm{mg}$ were shown to provide initial relief of NSAID-associated upper Gl symptoms (upper abdominal pain, discomfort, or burning) [12]. The results presented here demonstrate that treatment with esomeprazole 20 and $40 \mathrm{mg}$ maintained relief of these symptoms during a further 6 months of once-daily treatment. Esomeprazole-treated patients were also more likely to experience prolonged relief of other individual investigator-assessed upper Gl symptoms than those taking placebo. Moreover, compared with those receiving placebo, esomeprazoletreated patients reported better Gl symptom relief and HRQL as assessed using the GSRS and QOLRAD instruments.

The study had a number of limitations. First, patients were rerandomised from the acute studies even if their initial response had been to placebo, and this may have impacted on the study findings. For example, it appeared that patients taking placebo during the acute studies had a low relapse rate even when tak- ing placebo during the maintenance phase; this is consistent with a true placebo response. In theory, the higher relapse rates in patients initially treated with esomeprazole who then received placebo during the maintenance phase could be attributed to acid rebound. However, it is difficult to distinguish between acid rebound and recurrence of initial symptoms, the latter of which seems more likely. Most of the benefits of acid suppression were established by day 45 (because most cases of symptom relapse in placebo recipients had already occurred by this time point). It is unknown whether those taking esomeprazole during the maintenance phase would require continued therapy beyond the 6-month time point in order to achieve sustained benefits. However, taking the two phases of this study as a whole, it seems likely that a substantial proportion of patients would experience relapse of symptoms if treatment were stopped at this point. In practice, prescribers may well assess the need for continued maintenance treatment by a trial of drug cessation.

In the two studies described here and the two 4-week studies that preceded them, NSAID-associated upper Gl symptoms were strictly defined so as to differentiate them from symptoms more characteristic of GERD, primarily heartburn. For this reason, patients with a history of GERD were excluded from the studies. Moreover, the symptoms assessed as the primary variable in the study, namely 'upper abdominal pain, discomfort, or burning,' have been shown to be significantly increased by NSAID use [2].

Although selective COX-2 inhibitors appear to cause fewer upper Gl events than NSAIDs, it is clear that drug-related upper $\mathrm{Gl}$ symptoms remain a problem with this group of drugs 
Figure 4

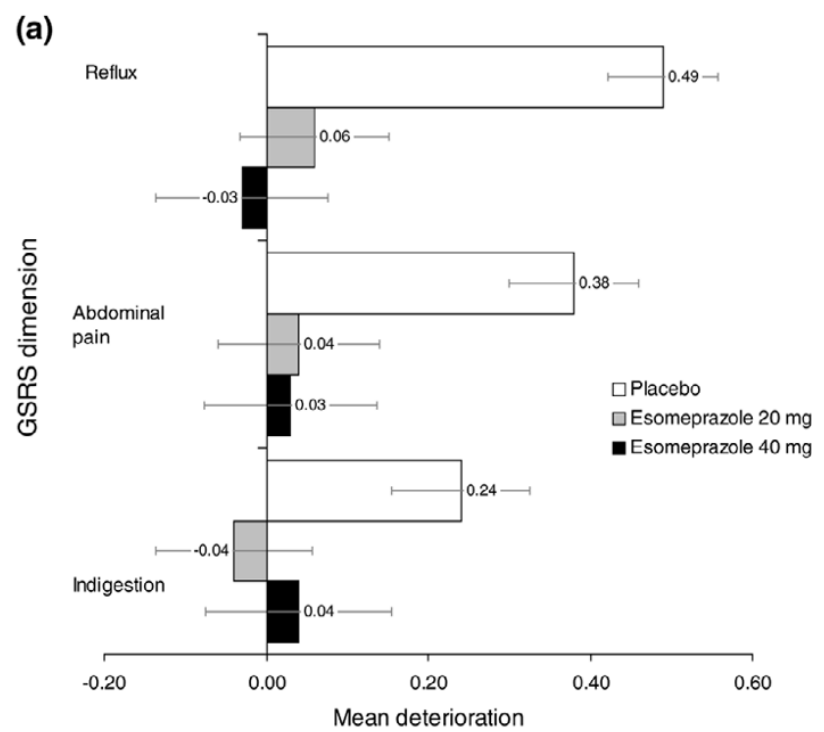

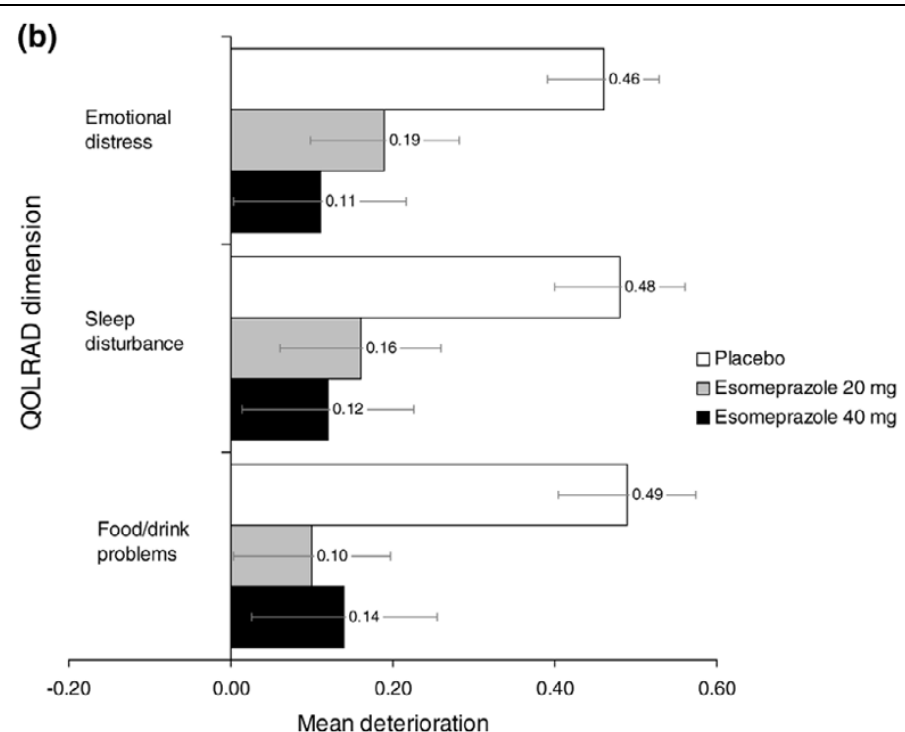

Score changes in patient-reported outcome scales. Mean (and standard error) score change in (a) Gastrointestinal Symptom Rating Scale (GSRS) and (b) Quality of Life in Reflux and Dyspepsia (OOLRAD) questionnaire (pooled intention-to-treat population).

$[5,16]$. When the studies were started, the use of selective COX-2 inhibitors was already substantial, and because upper Gl symptoms requiring co-therapy are problematic for patients taking these drugs as well as those taking non-selective NSAIDs, our study design allowed trial entry on either type of drug. Similar reductions in upper $\mathrm{Gl}$ symptom relapse rates to those seen in the whole study population were also observed for the subgroups, although esomeprazole $20 \mathrm{mg}$ did not achieve statistical significance over placebo within the smaller selective COX-2 inhibitor group. These data, in conjunction with studies demonstrating that at-risk patients have a significant ulcer risk reduction with esomeprazole therapy [17], offer clinicians important treatment options for users of non-selective NSAIDs or selective COX-2 inhibitors. Our study also supports the previously established finding that dyspepsia is less prevalent in older patients than in younger patients $[18,19]$. However, whether this is due to a true reduction, reduced perception, or a disinclination to report symptoms is unknown.

Limited data are available on long-term symptom control in patients with dyspepsia. Our results compare favourably with those of one randomised controlled trial in $H$. pylori-negative patients with dyspepsia [20]. Patients received omeprazole 20 mg once daily, ranitidine $150 \mathrm{mg}$ once daily, cisapride $20 \mathrm{mg}$ twice daily, or placebo for 4 weeks followed by 5 months of ondemand treatment with the same therapy. The proportions of patients with symptom relapse (that is, score of more than or equal to 3 on an amended 7-point Likert scale) at 6 months were $56 \%$ for omeprazole, $59 \%$ for ranitidine, $60 \%$ for cisapride, and $65 \%$ for placebo [20]. In our study, relapse rates of $26.1 \%$ to $39.1 \%$ were observed. However, due to differ- ences in study design between this study and our study, it is difficult to draw conclusions from these data.

\section{Conclusion}

The future use of selective COX-2 inhibitors is uncertain following the withdrawal of rofecoxib due to the risk of cardiovascular events. The results of these studies, however, show a benefit with esomeprazole therapy (20 and $40 \mathrm{mg}$ ) among patients taking either non-selective NSAIDs or selective COX2 inhibitors. These findings are of particular relevance for patients requiring long-term, continuous anti-inflammatory therapy, who may otherwise need to discontinue treatment because of upper Gl side effects.

\section{Competing interests}

$\mathrm{CJH}$ has received research funding and/or honoraria from AstraZeneca (Mölndal, Sweden), GlaxoSmithKline (Uxbridge, Middlesex, UK), Merck (Whitehouse Station, NJ, USA), NitroMed, Inc. (Lexington, MA, USA), Novartis International AG (Basel, Switzerland), Pfizer, Inc. (New York, NY, USA), Takeda Pharmaceutical Company Limited (Osaka, Japan), Serono International SA (Geneva, Switzerland), Wyeth (Madison, NJ, USA), and Grünenthal GmbH (Aachen, Germany). NJT has participated in consultant advisory boards sponsored by AstraZeneca and has received consultant's research support from TAP Pharmaceutical Products, Inc. (Lake Forest, IL, USA). JMS has received grant/research support from AstraZeneca, is a consultant to AstraZeneca, Merck, Novartis International AG, TAP Pharmaceutical Products, Inc., Pfizer, Inc., The GI Company, Inc. (Framingham, MA, USA), POZEN Inc. (Chapel Hill, NC, USA), Bayer Corp. (Emeryville, CA, 
USA), and GlaxoSmithKline, and has participated in Speaker's Bureaus for AstraZeneca, TAP Pharmaceutical Products, Inc., and Santarus, Inc. (San Diego, CA, USA). RHJ has received consultancy and speaker fees from AstraZeneca, Altana AG (Bad Homburg, Germany), and Reckitt Benckiser plc (Slough, Berkshire, UK). GL and JN are full-time employees of AstraZeneca. NDY has received speaker fees from a maker of PPIs, AstraZeneca, which financed the development of this manuscript.

\section{Authors' contributions}

All authors were involved in study design and manuscript preparation. $\mathrm{CJH}, \mathrm{NJT}, \mathrm{JMS}, \mathrm{RHJ}$, and NDY were responsible for data acquisition and interpretation. JN was involved in data interpretation. Data analysis was provided by GL. All authors read and approved the final manuscript.

\section{Acknowledgements}

This research was supported by a grant from AstraZeneca. We thank Claire Byrne and Steve Winter, from Wolters Kluwer Health (Chester, Cheshire, UK), who provided medical writing support funded by AstraZeneca. The other members of the NASA/SPACE author group are Herman Mielants (Belgium), Walter F Kean (Canada), Pavla Vavřincová (Czech Republic), Wolfgang W Bolten, Michael Buchner and Johannes Habbig (Germany), Gabriele Bianchi Porro (Italy), Jean-François Bergmann and Francis Philippe (France), Pàl Demeter (Hungary), Olav Bjørneboe (Norway), Dariusz Kleczkowski and Janusz Rudzinski (Poland), Jozef Rovenský (Slovak Republic), Anne Halland (South Africa), Angel Lanas (Spain), Kjell-Arne Ung (Sweden), and Atul Patel (UK).

\section{References}

1. Singh G, Ramey DR, Morfeld D, Shi H, Hatoum HT, Fries JF: Gastrointestinal tract complications of nonsteroidal anti-inflammatory drug treatment in rheumatoid arthritis. A prospective observational cohort study. Arch Intern Med 1996, 156:1530-1536.

2. Straus WL, Ofman JJ, MacLean C, Morton S, Berger ML, Roth EA, Shekelle P: Do NSAIDs cause dyspepsia? A meta-analysis evaluating alternative dyspepsia definitions. $A m$ J Gastroentero/ 2002, 97:1951-1958.

3. Jones RH, Tait CL: Gastrointestinal side-effects of NSAIDs in the community. Br J Clin Pract 1995, 49:67-70.

4. Lisse JR, Perlman M, Johansson G, Shoemaker JR, Schechtman J, Skalky CS, Dixon ME, Polis AB, Mollen AJ, Geba GP, ADVANTAGE Study Group: Gastrointestinal tolerability and effectiveness of rofecoxib versus naproxen in the treatment of osteoarthritis: a randomized, controlled trial. Ann Intern Med 2003, 139:539-546.

5. Silverstein FE, Faich G, Goldstein JL, Simon LS, Pincus T, Whelton A, Makuch R, Eisen G, Agrawal NM, Stenson WF, et al.: Gastrointestinal toxicity with celecoxib versus nonsteroidal anti-inflammatory drugs for osteoarthritis and rheumatoid arthritis: the CLASS study: a randomized controlled trial. Celecoxib Longterm Arthritis Safety Study. JAMA 2000, 284:1247-1255.

6. Wiklund I: Quality of life in arthritis patients using nonsteroidal anti-inflammatory drugs. Can J Gastroenterol 1999, 13:129-133.

7. Moayyedi P, Braunholtz D, Atha P, Dowell AC, Mason S, Axon ATR, on behalf of the Leeds HELP study group: The influence of dyspepsia, Helicobacter pylori status and irritable bowel syndrome on quality of life in the community [abstract]. Gastroenterology 1998, 114(4 pt 2):A231.

8. Singh G, Rosen Ramey D: NSAID induced gastrointestinal complications: the ARAMIS perspective - 1997. Arthritis, Rheuma- tism, and Aging Medical Information System. J Rheumatol Supp/ 1998, 51:8-16.

9. Elliott SL, Ferris RJ, Giraud AS, Cook GA, Skeljo MV, Yeomans ND: Indomethacin damage to rat gastric mucosa is markedly dependent on luminal pH. Clin Exp Pharmacol Physiol 1996, 23:432-434

10. Hawkey CJ, Karrasch JA, Szczepanski L, Walker DG, Barkun A, Swannell AJ, Yeomans ND: Omeprazole compared with misoprostol for ulcers associated with nonsteroidal antiinflammatory drugs. Omeprazole versus Misoprostol for NSAID-induced Ulcer Management (OMNIUM) Study Group. N Engl J Med 1998, 338:727-734.

11. Yeomans ND, Tulassay Z, Juhasz L, Racz I, Howard JM, van Rensburg CJ, Swannell AJ, Hawkey CJ: A comparison of omeprazole with ranitidine for ulcers associated with nonsteroidal antiinflammatory drugs. Acid Suppression Trial: Ranitidine versus Omeprazole for NSAID-associated Ulcer Treatment (ASTRONAUT) Study Group. N Engl J Med 1998, 338:719-726.

12. Hawkey C, Talley NJ, Yeomans ND, Jones R, Sung JJ, Langstrom G, Naesdal J, Scheiman JM, NASA1 SPACE1 Study Group: Improvements with esomeprazole in patients with upper gastrointestinal symptoms taking non-steroidal antiinflammatory drugs, including selective COX-2 inhibitors. $A m$ J Gastroenterol 2005, 100:1028-1036.

13. Revicki DA, Wood M, Wiklund I, Crawley J: Reliability and validity of the Gastrointestinal Symptom Rating Scale in patients with gastroesophageal reflux disease. Qual Life Res 1998, 7:75-83.

14. Wiklund IK, Junghard O, Grace E, Talley NJ, Kamm M, Veldhuyzen van Zanten S, Pare P, Chiba N, Leddin DS, Bigard MA, et al.: Quality of Life in Reflux and Dyspepsia patients. Psychometric documentation of a new disease-specific questionnaire (OOLRAD). Eur J Surg Supp/ 1998, 583:41-49.

15. Junghard O, Lauritsen K, Talley NJ, Wiklund IK: Validation of seven graded diary cards for severity of dyspeptic symptoms in patients with non ulcer dyspepsia. Eur J Surg Suppl 1998:106-111.

16. Bombardier C, Laine L, Reicin A, Shapiro D, Burgos-Vargas R, Davis B, Day R, Ferraz MB, Hawkey CJ, Hochberg MC, et al.: Comparison of upper gastrointestinal toxicity of rofecoxib and naproxen in patients with rheumatoid arthritis. VIGOR Study Group. N Engl J Med 2000, 343:1520-1528.

17. Scheiman JM, Yeomans ND, Talley NJ, Vakil N, Chan FK, Tulassay Z, Rainoldi JL, Szczepanski L, Ung KA, Kleczkowski D, et al:: Prevention of ulcers by esomeprazole in at-risk patients using non-selective NSAIDs and COX-2 inhibitors. $\mathrm{Am}$ Gastroentero/ 2006, 101:701-710.

18. Bode G, Brenner H, Adler G, Rothenbacher D: Dyspeptic symptoms in middle-aged to old adults: the role of Helicobacter pylori infection, and various demographic and lifestyle factors. J Intern Med 2002, 252:41-47.

19. Talley NJ, Evans JM, Fleming KC, Harmsen WS, Zinsmeister AR, Melton LJ III: Nonsteroidal anti-inflammatory drugs and dyspepsia in the elderly. Dig Dis Sci 1995, 40:1345-1350.

20. Veldhuyzen van Zanten SJ, Chiba N, Armstrong D, Barkun A, Thomson A, Smyth S, Escobedo S, Lee J, Sinclair P: A randomized trial comparing omeprazole, ranitidine, cisapride, or placebo in Helicobacter pylori negative, primary care patients with dyspepsia: the CADET-HN Study. $\mathrm{Am} J$ Gastroenterol 2005, 100:1477-188. 